\title{
Review of Studies on Corporate Annual Reports During 1990-2012
}

\author{
Atefeh Mobasher (Corresponding author) \\ University Putra Malaysia, Selangor, Malaysia \\ E-mail: whiterose14002002@gmail.com \\ Afida Mohamad Ali \\ University Putra Malaysia, Selangor, Malaysia \\ Faiz Sathi Abdullah \\ University Putra Malaysia, Selangor, Malaysia \\ Chan Mei Yuit \\ University Putra Malaysia, Selangor, Malaysia
}

Received: 12-12- 2012

doi:10.7575/aiac.ijalel.v.2n.2p.133
Accepted: 22-01- 2013

Published: 01-03- 2013

URL: http://dx.doi.org/10.7575/aiac.ijalel.v.2n.2p.133

\begin{abstract}
Corporate Annual Reports (CARs) are corporate communication tools which have been around for 75 years. They report company's progress, profits and losses. At first, reports were provided in English, because they were published in an English speaking context. After a while, non-English speaking companies started to publish CARs in English to attract international investments. So far studies on CARs considered themes in text and images of CARs, subgenres of CARs, rhetorical construction, discourse and genre structure. During the last two decade; however, not many studies have been conducted on CARs from a language perspective. We aim to evaluate those studies and provide insight for further research. Findings of previous studies revealed that CARs consist of various sections functioning as sub-genres that have features of their own. Researchers so far have been interested in management forewords section as it is considered to be the most widely read section of CAR, which are supposed to gain the trust of readers. Other sub-genres studied include: operational and financial performance, corporate history and mission statements. As modern CARs are considered to be multimodal, images that appear in CARs have also been studied.
\end{abstract}

Keywords: Annual Reports, Genre analysis, Theme analysis

\section{Introduction}

According to Plung and Montgomery (2004) modern Corporate Annual Reports (CARs) are corporate communication tools which were published approximately since 1827, in the United States. They appeared as a result of investors' demand to receive reports of the company's progress, profits and losses. The role and functions of CARs were not clear in their early days and issuing them has become mandatory by law since 75 years ago. At first, they were rather simple; including only financial data, and were published as columns in The New York Times or The Wall Street Journal. After a while, shareholders asked for detailed disclosures that were attested by certified auditors. Their demand influenced the standardization of the accounting profession. However, interpreting the reports was difficult for investors.

By the end of the twentieth century, CARs were divided into two sections: 1) the 10-K document which consisted of detailed financial information and, 2) Summary of Annual Reports (SAR) which comprised of narrative portion of the earlier version of CARs written in the layman's term.

CARs have been the subject of many extensive studies, from different perspectives. Some of the studies on Annual Reports are on the practice of voluntary disclosure in CARs and their effects on the market (Beattie, McInnes, \& Fearnley, 2004; Linsley \& Shrives, 2006), use and abuse of graphs in CARs (Beattie \& Jones, 1994; Beattie \& Jones, 1992), gender diversity and the images of the women in the CARs (Anderson \& Imperia, 1992; Benschop \& Meihuizen, 2002; Bernardi, Bean, \& Weippert, 2002, 2005; Preston, Wright, \& Young, 1996), readability of CARs (Beattie \& Jones, 1994; Courtis, 1995; Courtis \& Hassan, 2002), content and theme analysis (Conaway \& Wardrope, 2010; Jameson, 2000; Kohut \& Segars, 1992), discoursal strategies (Thomas, 1997), use of narrative discourse(Jameson, 2000), use of symbolism (David, 2001), relationship between text and context in a hermeneutic perspective (Prasad \& Mir, 2002), subgenres of CARs (Conaway \& Wardrope, 2010; Delahaye, Booth, Clark, Procter, \& Rowlinson, 2009; Rogers, 2000; Thomas, 1997; Williams, 2008), rhetorical construction (Hyland, 1998), discourse and genre studies (Garzone, 2004; Nickerson \& De Groot, 2005; Rutherford, 2005). However, only a few studies considered CARs from language perspectives. The present paper aims to review studies conducted on CARs from language perspective, identifying the limitations in previous studies and providing insight for further research. 


\section{Method}

To select articles for the present review, the key word 'Annual Report' was searched in Google scholar for the time range of 1990 to 2012. The search results showed a few research studies related to the field of language, using languages theories for analysis. From the results found by Google scholar, only empirical studies from the field of language were selected.

\section{Critical reviews}

Critical reviews of the studies conducted are presented in two sections. Studies conducted during 1990-2000 and studies conducted during 2001-2012. Each period is further divided into two sections: studies conducted on texts of CARs, and studies conducted on images of CARs.

\subsection{Studies during 1990-2000}

During 1990 to 2000 a few studies considered the Corporate Annual Reports. They were mainly limited to a specific section within the report: management statement. These studies consist of six research studies conducted on CAR text. During this period no language study was conducted on CAR images.

\subsubsection{Text analysis studies}

Text analysis studies during this period consist of theme analysis studies and negative themes, linguistic choice, use of metadiscoursal resources, audience need analysis and report narrators.

\subsubsection{Theme analysis on CEO's letters}

Kohut and Segars (1992) studied presidents' letters with regard to the themes in low performing and high performing companies. Reason for conducting a theme analysis on the CEO's letters was indicated as the limitation of previous studies on the qualitative sections of Annual Reports. The corpus came from top 500 firms listed by Fortune magazine. To select the samples, they ranked all of the firms on the list based on the 'return on enquiry' and the result were fifty letters which were divided into 25 top performing and 25 low performing companies. It is not clear what was the rank of other firms on the list and why they could not be included in the analysis. Then a content analysis was conducted by the researchers on the letters to find the most frequent theme. The unit of the analysis was set on the each individual sentence. Nothing was mentioned about the reliability of the analysis or inter-coder reliability. They found six recurrent themes in both sets of data: "a) environment, b) growth, c) operating philosophy, d) markets and products, e) unfavorable financial references, and f) favorable financial references" (p. 7). Nonetheless, themes that appeared on low performing companies were different from that of high performing companies by putting more emphasis on future plans, projects and possible achievements.

\subsubsection{Linguistic choice during loss making}

Thomas (1997) also considered management statements of one company during a time period which started with profit making and ended with severe losses. The purpose of study was to examine how good news and bad news affects manager's message delivery and how the linguistic choices by the company manager could be interpreted. During loss making there were noticeable increase in the application of passive construction, process verbs, being verbs and nonhuman agents. Pronoun 'we' decreased drastically and inanimate nominal groups increased by $80 \%$. Yet, there was a noticeable decrease in the application of doing verbs. These changes initiated the feeling that no particular person was responsible for the situation and it was caused by circumstances. The study was limited to the CEO's massage of one company during a time range of prosperity to loss making. Moreover, nothing was mentioned about the reliability of analysis.

\subsubsection{Use of metadiscoursal resources in CARs}

Hyland (1998) also studied management statement, but with regard to the use of metadiscourse items in CEO's and director's letters. He conducted a comparative analysis on 137 CEO's letters and 110 directors' letters from Hong Kong stock exchange between the years 1992-1994. He included all of the available letters. The significant of the study was stated as limitations in research studies on rhetorical elements of corporate management forewords. The text was analyzed and coded by three analysts and the reported inter rater reliability was high. The results of analysis indicated that metadiscourse items were used in CEO's letters two and half times more often than director's letters and included six times more interpersonal items. The reason for such noticeable difference was stated as the difference in the communicative purpose of the two types of letters rather than difference in format.

\subsubsection{Negative theme as a communication strategy}

Crombie and Samujh (1999) claimed that negative messages or themes could sometimes be used as a communication strategy. They conducted a case study on the content of one annual executive letter of a small New Zealand company and considered the surface linguistic features, immediately recoverable meanings and meanings that can only be recovered through considering the context. The analysis revealed that the discussed problems were either minor ones or they have already been solved which can be an indication of the efficiency of management in the eyes of the readers. This strategy which is a high-risk one is actually applied as a cover for more major problems. The authors did not mention any gap in previous studies with regard to the issue at hand and no specific reason was provided as the criteria of sample selection. Furthermore, the criteria and reliability of analysis was not discussed. 


\subsubsection{Audience needs analysis}

Rogers (2000) considered spoken texts produced by CEOs. Her samples consisted of eight presentations which met three criteria: they were all presented at NYSSA, reported corporate earnings, and were available in videotapes. Besides, none of them were presenting good news. The limitations of previous literature were indicated as a lack of audience need analysis. She extended the genre analysis beyond the analysis of the spoken text of CEOs' presentations and included context analysis and audience response to CEOs' presentation. The result of analysis suggested that the presentations performed by company CEOs were highly informational while secondarily relational. It also revealed that the content needs of the audience were to some extent met, yet off-balance sheet information was ignored all together. However, nothing was mentioned about the reliability of analysis.

\subsubsection{Using multiple narrators for CARs}

Jameson (2000) analyzed shareholders' report of randomly selected 100 mixed return funds companies and 100 top return funds companies. No specific gap or limitation was mentioned in previous studies and the purpose of analysis was indicated as how CAR writers deal with difficult situation while reporting ambiguous situations. The reports were analyzed based on two methodological approaches: 1. narrative theory and, 2. computer analysis. They were analyzed as written text, and data about the linguistic, stylistic and structural features of the text was gathered. All verbal components were included in the analysis and only footnotes, portfolio of investment, financial statement, list of top holdings, charts and tables were excluded. T-tests and chi-square tests were run to measure the significant difference between the texts that reported mixed returns and those which reported top return. He discovered that the reports were written using multiple narrators to moderate the bad news in mixed return reports; and influence the reader both emotionally and intellectually in their decision making through providing readers the freedom to choose their own interpretation from several perspectives. Among the findings were also three different types of themes in both sets of data: self-justification, blame and adjusted perspectives. However, companies with mixed return were significantly less direct in their report than top return companies. As the author apparently analyzed the whole text of shareholders' report, he reported there are sub-genres within the genre of shareholders' report.

\subsubsection{Studies on the pictures}

During this time period some studies have been conducted on the images of Annual Reports, like studies on images of women in CARs (Anderson \& Imperia, 1992) and visual design (Seidman, 1992), of the CARs. However, those studies were not supported by language theories.

\subsection{Studies during 2001-2012}

Studies conducted on CARs during this period could be divided into two major sections: studies on the text of CARs and studies on images that appear in CARs. However most of the studies during this period are text analysis studies.

\subsubsection{Text analysis studies}

Annual Reports consist of different sections that according to the findings of studies on them could be considered as sub-genres. These sub genres have been the subject of text analysis studies during 2001-2012. The nine text analysis studies conducted during this period consist of studies on linguistic features of CARs, move analysis studies, sub-genres within CARs, theme analysis, interdiscursivity, and use of metadiscoursal resources.

\subsubsection{Discoursal features of CARs}

Garzone (2004) in a pilot study singled out ten CEO's letters from Italian companies and 10 from other European and American companies. CEO's letters as management foreword are considered as the most widely read section of Annual Reports. The purpose of analysis was to consider the discoursal feature and cultural markedness in these texts. The researcher was looking for any possible meaningful variation between these two groups of reports. The analysis revealed that the most frequent words were not lexical words but the personal pronoun ' $w e$ ' and its associated possessive adjective 'our' which creates a sense of inclusiveness. She also discovered that Italian companies were weak with regard to the use of computer (internet) as a medium of communication and it was obvious in their infrequent use of multimodality. Besides, interferences of Italian conventions were also obvious as the writers were trying to create an objective style through frequent use of passive voice. Italian reports were also weak with regard to creating a sense of sharing with the investors. Her findings once again affirmed the fact that common genres like management forewords could display variation in their structure and style when they come from different cultures. Nothing was mentioned about the inter-rater reliability.

\subsubsection{Sub genres within CARs}

Rutherford (2005) also focused his study on a sub genre of CARs. He considered Annual Reports as a broader accounting narration genre, which contains more specific genres like the operational and financial review. The purpose of his study was to identify the generic conventions of this particular text type, and the sample of his study came from UK1000. Companies in financial service and property sectors and the ones which did not provide capitalization or prepared their report according to American standardization were deleted from the list to have matched samples. After requesting the remaining companies for their reports, those which did not provide them were also deleted. From the companies which provided their report, only 68 published OFRs as a sub section. Then these companies were divided into seven groups and five pairs: "a) loss making versus least profitable, b) least profitable versus most profitable, c) loss making versus most profitable, d) smallest versus largest and e) lowest geared versus highest geared" (Rutherford, 2005, p. 357). The results revealed stability in patterns of usage in the text of operational and financial review and 
proved it as a distinct sub-genre. The study also found evidence that poorly performing companies tend to employ positive language more often. The sub genres identified within OFRs employed differential propensity in their positive language plus difference in marketing strategy, corporate recovery, self-reference, comparative analysis and gearing. However, nothing was mentioned about the reliability of analysis and coding.

Another study which focused on a sub-genre of CARs was conducted by Delahaye, Booth, Clark, Proctor, and Rowlinson (2009). They studied corporate history. The purpose of the analysis was to identify and define this specific sub-genre. To fulfill this purpose, they studied texts of 85 historical narratives of British and US companies including both printed and webpage texts. The sample consisted of 37 British companies ranked according to yearly revenues and 49 US companies matched with British ones based on industry. It is not clear why the sample were chosen from fortune 500 for British companies or why they have been chosen based on their revenues. No justification was provided for the choice of method as there are different methods of content and thematic analysis, and nothing was mentioned about the inter rater reliability. The gap in previous studies was indicated as negligence about the genre of corporate history in organization theory. The study revealed recurrent formal features and elements of thematic contents. These qualities identify 'corporate history' as a genre.

Mission statement could also be a sub-genre within the genre of Annual Reports. Williams (2008) studied the text of mission statements from Fortune 1000 companies. She initially selected 50 companies: 25 from high performing and 25 for low performing companies. Her final samples consisted of 27 mission statement, 13 of which belonged to high performing companies and 14 to low performing companies. Her explanation about the samples is rather confusing; because further in the text she states that she analyzed all 48 samples. However, the table provided reveals the results of analysis for 27 companies. Before analyzing the text, she defined mission statement as a text that provides us with two pieces of information about the company. It informs us about the nature of the company and its conduct. A content analysis was applied on two sections: mission statement and value statement. Some companies included value statements in their mission statement section; and some did not. For the samples which did not included value statements in their mission statement, the researcher looked for the company's value statement and added it to mission statement. The consistency of analysis was established through inter rater reliability. The higher performing companies included the proposed nine components (proposed in earlier studies) more frequently than the low performing ones and the difference was significant for three of those components. Besides, the difference between the two sets of samples with regard to the application of first person and plural self-references was significant, as higher performing companies used it more often. The two sets of samples were similar in strategies employed to build corporate identities and images, but were different in their emphasis on values and the goodwill recipients.

\subsubsection{Move and strategy identification}

A study which embarked on the genre analysis of Corporate Annual Reports was conducted by Nickerson and Groot (2005). Their analysis was limited to the comparison of British chairman statements and CEO's statements with Dutch CEO's statements; and they came up with five move patterns (1. business letter layout, 2 . financial performance + (past) operations, 3. financial performance (future), 4. strategy, and 5. credentials) and 12 strategies (1.salutations, 2. close, 3. establishing credentials, 4 . setting the economic scene, 5. providing corporate financial context, 6 . providing special financial performance details, 7. summarizing operational performance in the past, 8. providing details on the board, 9 . speculating on future performance, 10. providing future objectives, 11. emphasizing a strong workforce, 12. communicating business strategies). In conclusion, they stated that the communicative purpose of all three sub genres (British chairman statements, CEO's statements and Dutch CEO's statements) was to gain the confidence and trust of the readers. However, they also identified variation in these sub genres: the British CEO's statements were informational, but the Dutch CEO's statements were both informational and relational. On the other hand, the British Chairman's statements were relational and promotional. It seems that cross cultural variations also appear in sub genres.

However, the study had some shortcomings: first, nothing was mentioned about the process of move identification. Second, the identified moves did not have any specific constituents (steps/strategies). In order words, the strategies identified were not exclusive to any move.

De Groot (2008) also conducted move analysis on three sections of CARs. The samples of her study came from Netherland and England stock exchange, and consisted of 22 CARs for each country. Her sampling was a mixture of purposive and cluster sampling. Her criteria of choice included being exclusively national, having large to mid-size capital base, and English being the main language of CAR publication. Then, samples were matched based on industries that included 15 industries. The analysis was on the non-financial sections of Annual Reports which she divided into three sections or sub-genres: management statement, corporate profile and operational review. The functional description for demarcation of rhetorical move and strategies were either new or were indirectly derived from previous studies on rhetorical structures in professional genre. She came up with 17 moves and 34 strategies for the three sections analyzed.

The sub-genre of management forewords consisted of 20 Dutch-English CEO's letters, 18 British CEO's letters and 16 British chairman's letter. The results of analysis revealed 10 moves and 20 strategies. There were statistically significant variations between the Dutch and British management texts for three elements: 1. anticipating reader orientation, 2. salutation to reader strategy and, 3 . addressing the reader. 
The sub-genre of corporate profiles from these two cultures consisted of 21 Dutch-English and 20 British profiles. The analysis revealed 5 moves and 11 strategies. The significant difference between two cultures appeared in the application of the move 'communicating corporate strategy'. This move was used by Dutch companies more often.

Operational review consisted of 22 Dutch-English text and 20 British ones. The analysis revealed 9 moves and 13 strategies. The two nations also displayed significant difference in the sub-genre of operational review. The strategy 'general profile of the company' plus the combination of the moves 'detailing the product', 'targeting the market', 'reporting on operational performance' were used by Dutch companies more often, while the move 'speculating on future performance' was significantly applied by British companies.

The consistency of analysis was considered through inter rater reliability. De Groot stated the variations in these subgenres as subtle differences that were due to cultural difference.

Some of the shortcomings of her study are: not defining corporate profile and operational review, and not providing any justifications for comparing British chairman letter with Dutch CEO's letter. She also identified 17 moves and 34 strategies. However, these strategies were not exclusive to any move which is unusual. Of 17 moves listed, move 17 does not appear in any of the analyzed sections. Moreover, she failed to provide any move model for any of the three sections analyzed.

\subsubsection{Theme analysis on CARs}

De Groot (2008) also considered the intercultural variations of the themes in CARs. However, she published a more detailed result of her analysis on management forewords in 2006 as a research article. She compared CEO's statements from Dutch companies with CEO's and chairman's statements from British companies (20 Dutch-English CEO letters, 18 British CEO letters and 16 British chairman letters). Her sampling procedure has already been explained in the previous section (3.2.1.3). In her analysis she followed the framework proposed by Ryan and Bernard (2003) and identified 97 themes in these texts. Fifteen of the identified themes occurred about $50 \%$ more often in all three texts types. The results of her analysis revealed four significant differences: 1) theme of 'corporate strategy' appeared significantly with more details in British CEO's statements; however the theme 'board details' occurred significantly more often in British chairman's statements. 2) CEO's statements for Dutch companies contained significantly more items of "HRM/people" and "corporate governance" themes than CEO's statement for British companies. 3) The theme "CSR" was significantly more frequent in the text of British chairman's statements than Dutch-English CEO's statements. 4) Statements of British CEOs included significantly more details on the theme "dividend" than the other two.

De Groot (2008) also analyzed two other sections of CARs with respect to themes presented following the same framework mentioned above. Overall, in all three sections she identified 192 different themes; however she based her comparison on the themes that occurred at least in $50 \%$ of each section. The results of comparison for management forewords were already covered according to her 2006 article. Her analysis on corporate profile consisted of 21 DutchEnglish profile and 20 British ones, which revealed 6 frequent themes. The texts from both cultures provided the same types of information in this section and there wasn't any significant difference between them.

The samples of operational review consisted of 22 Dutch-English text and 20 British ones, and 16 themes were identified whereby their frequency of occurrence was equal or higher than $50 \%$. The results of analysis and comparison revealed that the theme 'cost management' appeared significantly more often in British texts and the theme 'identity of market' appeared significantly more often in Dutch texts.

The consistencies of analysis for her 2006 and 2008 studies were considered through inter rater reliability.

In sum, findings of De Groot, Korzilius, Ickerson and Gerritsen (2006) and De Groot (2008) confirm that both cross cultural and cross textual variation might exist in themes that appear in CARs. Cross textual variations are usually due to the difference between the communicative purposes of these two sections.

Another comparative thematic analysis of CEO's letters was conducted by Conaway and Wardrope (2010). The corpus of the study consisted of 30 CEO's letters extracted from U.S. companies and 24 CEO' letter from Latin American companies coming from multiple countries. The choice of Latin American companies was on the assumption that all Latin American countries have similar corporate communication culture and strategies. When the samples do not come from two matched groups, the differences identified could be due to many factors. Nothing was mentioned about the criteria of CAR selection and method of sampling. Another shortcoming of the study is that the consistency of analysis was not considered.

The texts were analyzed in terms of thematic structure, style (readability) and cultural differences. Grounded theory was adopted as the support for theme analysis and a corpus tool for content analysis called NVivo8 was used to run the analysis. The results revealed that Latin American letters contained twice more topics in their letters than U.S. letters and these extra topics were not related to the financial reporting.

Stylistic analysis revealed that American letters were longer than Latin American letters, yet Latin American letters contained more topics. Latin American letters also contained more passive constructions than U.S. letters. In short, Latin American letters revealed characteristics of high-context cultures. On the contrary, American letters were more systematic and sequential. The differences between two sets of samples were indicated as the result of stylistic differences rather than cultural variations. However, the consistency of analysis was not discussed. 


\subsubsection{Interdiscursivity in the study of CARs}

According to Bhatia (2010), to understand a professional text properly, all resources related to it needs to be considered. In his article on corporate communication, he argued that to analyze any professional communication comprehensively, one needs to consider textual and intertextual resources, generic conventions, professional practices, and professional cultures. Any framework which does not consider all of them cannot offer a comprehensive understanding of a specific genre. He tried to explore the nature of interdiscursivity in genre theory and provided three examples of interdiscursivity analyses, one of which was Corporate Annual Reports. The corpus came from 15 Hong Kong stock exchange listed companies between the years 1988 to 2005. The analyst divided the text into four sections: accounting discourse, discourse of finance, public relations discourse and legal discourse. A brief explanation for the function of these four sections was provided and it was claimed that although they were placed in the same document, accounting information is considered as the most important section of CARs which only consists of facts and numbers approved by independent auditors. Next was the economics section which gives an account of company's performance, presumably based on the first discourse, but it is not certified by those independent auditors. The reason for positioning both texts in the same 'interdiscursive space' might be to implicitly create the impression that the second is a true representation of the other. Here, the interdiscursivity came from appropriation of socio-pragmatic space. The analysis indicated that the different discourses within the same space differed in their accessibility to their readership and there were considerable variations in their technicality and complexity of the information.

\subsubsection{Use of Metadiscourse Items in CARs}

De Groot (2008) also considered use of metadiscourse items in CAR texts. The theory and framework of analysis came from Hyland (1998) and Hyland and Tse (1998). The gap in previous studies was stated as limited studies on the use of metadiscourse items in CAR texts. The result of analysis and comparison revealed significant cultural variations in all three analyzed sections of CARs. It was concluded that cross-cultural variations affect the choice of metadiscourse items.

The primary focus of both 'Dutch English' and British management texts were on defocalizing and mitigating the message, enforcing the message, evaluating the message, and establishing the 'reader sender' interaction. The significant variation appeared in three areas: 1) Dutch texts over-represented frame markers in the form of text staging signals. 2) British texts 'under represented' interactional engagement markers. 3) British texts also contained larger numbers of 'self-reference' in the form of management related nouns.

In corporate profile section, both British and 'Dutch English' texts focused on transitions in the form of conjunctions and exploratory code glosses. The second common area of focus was interactional resources which contained hedges, emphatic and evaluative references, and self-mentions. With regard to the variations, Fisher's Exact test revealed two significant differences. 1) Larger number of 'Dutch English' CARs contained textual boosters, 2) larger numbers of British profiles contained collective nouns as a means of establishing self-reference.

In operational review section, the common area of focus for both British and Dutch operational reviews was transitions in the form of conjunctions and phrase relating ideas, and code glosses which clarified textual information. Chi-Square test revealed only one statistically significant distinction between two groups of texts: larger numbers of 'Dutch English' reviews contained frame markers indicating stages in the text.

\subsubsection{Studies on the images of CARs}

Images of CARs have also been studied from different perspectives. Here, only the studies that used language theories for analysis are reported, which consist of semiotic studies of the images, move and theme analysis on images, and communicative purposes of the images that appear in CARs.

\subsubsection{Myth making through images}

David (2001) took a semiotic approach to the study of images in CARs, trying to reveal how designers of reports choose images and themes that could create "positive cultural myths". The corpus of the study came from two well-known companies in America (General Electric and Microsoft). The analysis was conducted qualitatively, and no systematic design or method was presented for the analysis except for the fact that the analysis was conducted based on the theory proposed by Barthes. The reliability of analysis was also not stated. However, the gap in previous studies has been indicated as no clear criteria of judgment for narrative section of CARs. The author only described the pictures used by these two companies; and claimed that CARs have dual purposes: disclosing companies' progress along with imparting companies' values. He further elaborates that image could influence the reader to interpret the data presented in the text of CARs emotionally and positively. At the end, it was suggested that two processes were required to judge the narrative section of the Annual Reports. First, the company's yearly claims should be examined and compared with its operation. Second, the visual and textual design of CARs needs to be analyzed to find how it might be trying to create myths.

\subsubsection{Move and strategy analysis on pictures of CARs}

De Groot (2008) also considered moves and strategies in images of CARs from England and Netherlands. She analyzed the images and their adjacent text fragments for their rhetorical functions in three sections of management forewords, corporate profile and operational reviews.

The photo related comments in management forewords consisted of 12 'Dutch English' CEO letter, 13 British CEO letters and 9 British chairman's letter. Rhetorical functions of the images and their adjunct text fragments of 
management forewords did not reveal any significant variation across the two cultures. Both cultures were focused on the personalized identification of the company. For both countries, the adjacent text fragments with headings highlighted the relevance of the information in the succeeding sentences and of the content of the photos. Three moves and five strategies were identified for the images; and 10 moves and 16 strategies were identified in photo related comments of images in this section.

The corporate profiles that contained images consisted of 8 Dutch profiles and 10 British ones. But comment related photos for this section only appeared in 3 Dutch profile and 8 British ones. Analysis of the visual moves and strategies in photos and photo related comments in the corporate profiles did not also reveal any significant variation between two cultures. However, 6 moves and 11 strategies were identified for images in this section; and 7 moves and 11 strategies were identified in photo related comments of these images. The rhetorical focus of both the photos and text related photos were on the general identification of the company.

The operational reviews that contained images consisted of 15 'Dutch English' texts and 17 British ones. The photo related comments appeared in 13 'Dutch English' texts and 15 British ones. In this section also there were no statistically significant difference between photographs and the photo related comments of the two cultures. Seven moves and 12 strategies were identified for images, and 15 moves and 26 strategies were identified in photo related text fragments. The most frequent moves and strategies for both cultures were 'identifying the company', 'describing the corporate products or services', and 'reporting on operational results'.

In sum, the analysis did not reveal any significant differences in rhetorical function of images and the image related comments between British and Dutch CARs.

The shortcoming of this study is that she has no theoretical support to identify moves in pictures. Besides, moves, as the largest unites of a genre, have been defined for text rather than picture. To be realized, a move need steps/strategies as it constituents and those steps/strategies need to appear within the boundaries of that particular move. It is not clear how she decided about move boundaries of the pictures and how she decided a particular picture is a move and another picture is a strategy of that move. Moreover, pictures that appear in a particular genre are part of that genre; however without the text they are just random pictures with no function. Consequently, they cannot function as moves, but they can stand as strategies to support the textual moves to realize.

\subsubsection{Themes presented in images of CARs}

Besides the rhetorical function of images of CARs, the thematic content of its images were also investigated by De Groot(2008). She presented the results of her study on management forewords of Dutch and British companies in her 2006 article. The texts which accompanied images consisted of 17 'Dutch English' CEO letters, 16 British CEO letters and 14 British chairman letters. Her framework of analysis actually came from Kress and Van Leeuwen (2006; 2001). She identified 23 themes in this section, but the most frequent themes were "management members", "work place" and "employees". With regard to the significant variations between two corporate cultures, CEO's statement of Dutch companies contained significantly more items of 'all executive directors'; on the other hand British CEO's statements had higher scores for 'female employees'. Male employees were not included in the pictures of any Dutch CEO's statement; however, they appeared significantly in British CEO's statements. Finally, pictures of 'non-executive' chairman appeared only in British chairman's statement.

The other two sections of CARs were also studied by De Groot (2008) following the same framework and on the same CARs. In corporate profile section, images appeared in 8 'Dutch English' profiles and 10 British profiles. Four main themes were identified. However, the results of Fisher's exact test revealed that the theme "male employees" and "work place" appeared significantly more often in the British texts.

In operational reviews, 22 'Dutch-English' reviews and 20 British reviews contained images. Five main image themes were identified, but Chi-square and Fisher's Exact test revealed no significant difference between the image themes of Dutch and British CARs. The consistency of analysis was considered through 'inter rater' reliability.

In sum, two out of three CAR sections studied revealed significant differences in two cultures with regard to image content.

\subsubsection{Communicative purposes of CAR images}

The communicative purpose of documentary photographs in CARs originating from Netherlands and Britain was also investigated by De Groot (2008). Phone interviews and emails were used to interview informant on the criteria of choosing images and their communicative purpose. Her study used convenient sampling and included only the London based and Amsterdam based companies (12 Dutch companies and 5 British ones) to avoid redundancy and save time. The interview results revealed seven criteria for choosing photographs from which four were common between British and Dutch informants '1) consistency in corporate information; 2) logical relation to corporate philosophy; 3 ) clear and purposeful meaning; 4) supportive of (central) theme in the report” (p. 79). The criteria which were not common between British and Dutch informants were “1) appeal to the readers' perception; 2) reflection of (historical) development; 3) explanation of textual information.

The informant also provided the general communicative purpose of the images, which means they did not provide the communicative purpose of each individual picture. Eight different communicative purposes were listed and seven of them were common between British and Dutch informants: "1) to visually illustrated the corporate identity; 2) to provide company with a personal face; 3 ) to emphasis the added value of the product/services; 4) To emphasize high 
capacity/professionalism; 5) to support the company's marketing; 6) to establish a central theme in the report; 7) to appeal to the reader's attitude'. The British informant added one more purpose 'to add to the readability of the text' ( $\mathrm{p}$. 80).

Overall, the British and Dutch informants were almost in unison on the criteria of choosing the images and their communicative purpose, which might indicate that they are generally common in Corporate Annual Reports.

\section{Conclusion}

Findings of the presented studies confirmed that there are sub-genres within the CARs that can stand as independent genres like management forewords, mission statements, corporate history, etc (Delahaye, et al., 2009; Garzone, 2004; Nickerson \& De Groot, 2005; Rutherford, 2005; Williams, 2008). However, management statements are the most widely read sections within Annual General Reports. Besides, CARs vary both inter-culturally and cross-textually with regard to the discoursal features, use of metadiscourse items, move patterns and content (De Groot, 2008). It was also revealed that CAR texts of loss-making companies and profit-making companies vary with regard to their language style and content. Companies tend to apply different strategies to reveal bad news or losses: they focus on future achievements, apply passive construction, process verbs and non-human agents or inanimate nominal group, they use multiple narrators and tend to be less informative (Kohut \& Segars, 1992; Thomas, 1997; Jamson, 2000; Roger, 2000). Another important finding was that bad news could be used strategically to convey the message that the managers are experts and can handle difficult situations (Crombie \& Samujh, 1999). The studies that analyzed the text for metadiscourse items discovered that the communicative purpose of the text influences the choice of metadiscourse items and there exist cross cultural variations with regard to their use (Hyland, 1998; De Groot, 2008). However, studies conducted on CARs are limited. Future studies could fill the gap in those areas mentioned in the following section.

\section{Further studies}

So far, very few studies have been conducted on CARs from language perspective and the corpuses analyzed are mainly in English and come from western countries. However, CARs from eastern countries have been neglected. Future research on CARs need to focus on CARs from countries where English is not the first language.

Genre analysis studies on CARs is also limited to one study conducted by De Groot (2008). There is a need to consider the genre content and structure of different sections within CARs using corpus analysis tool.

The modern Corporate Annual Reports are multimodal in nature, consisting of both text and images. Consequently, they also need to be considered from multimodal perspective. Images of CARs need to be studied with regard to their function and communicative purpose (both reader and writer perspectives), their relations to the text and their influence on CAR readers.

Studies on the use of metadiscourse items in Annual Reports is also surprisingly limited and there seems to be a dire need to consider them in CARs including all sections of Annual Reports; considering how they are used to influence reader and create a positive corporate image.

\section{Reference}

Anderson, C. J., \& Imperia, G. (1992). The corporate annual report: A photo analysis of male and female portrayals. Journal of Business Communication, 29(2), 113-128.

Beattie, V., \& Jones, M. (1994). An empirical study of graphical format choices in charity annual reports. Financial Accountability \& Management, 10(3), 215-236.

Beattie, V., \& Jones, M. J. (1992). The use and abuse of graphs in annual reports: theoretical framework and empirical study. Accounting and Business Research, 22(88), 291-303.

Beattie, V., McInnes, B., \& Fearnley, S. (2004). A methodology for analysing and evaluating narratives in annual reports: a comprehensive descriptive profile and metrics for disclosure quality attributes. Paper presented at the Accounting Forum.

Benschop, Y., \& Meihuizen, H. E. (2002). Keeping up gendered appearances: representations of gender in financial annual reports. Accounting, Organizations and Society, 27(7), 611-636.

Bernardi, R. A., Bean, D. F., \& Weippert, K. M. (2002). Signaling gender diversity through annual report pictures: a research note on image management. Accounting, Auditing \& Accountability Journal, 15(4), 609-616.

Bernardi, R. A., Bean, D. F., \& Weippert, K. M. (2005). Minority membership on boards of directors: the case for requiring pictures of boards in annual reports. Critical Perspectives on Accounting, 16(8), 1019-1033.

Bhatia, V. K. (2010). Interdiscursivity in professional communication. Discourse \& Communication, 4(1), 32-50.

Conaway, R. N., \& Wardrope, W. J. (2010). Do their words really matter? Thematic analysis of US and Latin American CEO letters. Journal of Business Communication, 47(2), 141-168.

Courtis, J. K. (1995). Readability of annual reports: Western versus Asian evidence. Accounting, Auditing \& Accountability Journal, 8(2), 4-17. 
Courtis, J. K., \& Hassan, S. (2002). Reading ease of bilingual annual reports. Journal of Business Communication, 39(4), 394-413.

Crombie, W., \& Samujh, H. (1999). Negative messages as strategic communication: A case study of a New Zealand company's annual executive letter. Journal of Business Communication, 36(3), 229-246.

David, C. (2001). Mythmaking in annual reports. Journal of Business and Technical Communication, 15(2), 195-222.

De Groot, E. (2008). English annual reports in Europe. Unpublished doctoral dissertation Unpublished doctoral dissertation, University of LOT: Netherland.

De Groot, E., Korzilius, H., Ickerson, C., \& Gerritsen, M. (2006). A corpus analysis of text themes and photographic themes in managerial forewords of Dutch-English and British annual general reports. Professional Communication, IEEE Transactions on, 49(3), 217-235.

Delahaye, A., Booth, C., Clark, P., Procter, S., \& Rowlinson, M. (2009). The genre of corporate history. Journal of Organizational Change Management, 22(1), 27-48.

Garzone, G. (2004). Annual Company Reports and CEOs' Letters: Discoursal Features and Cultural Markedness. In M. Gotti (Ed.), Intercultural aspects of specialized communication (pp. 311-341). Bern: Peter Lang.

Hyland, K. (1998). Exploring corporate rhetoric: metadiscourse in the CEO's letter. Journal of Business Communication, 35(2), 224-244.

Hyland, K., \& Tse, P. (2004). Metadiscourse in academic writing: A reappraisal. Applied Linguistics, 25(2), 156-177.

Jameson, D. A. (2000). Telling the investment story: A narrative analysis of shareholder reports. Journal of Business Communication, 37(1), 7-38.

Kohut, G. F., \& Segars, A. H. (1992). The president's letter to stockholders: An examination of corporate communication strategy. Journal of Business Communication, 29(1), 7-21.

Kress, G. (2006). Reading images: The grammar of visual design (second ed.). London: Routledge.

Kress, G., \& Van Leeuwen, T. V. (2001). Multimodal discourse: The modes and media of contemporary communication. London: Arnold.

Linsley, P. M., \& Shrives, P. J. (2006). Risk reporting: A study of risk disclosures in the annual reports of UK companies. The British Accounting Review, 38(4), 387-404.

Nickerson, C., \& De Groot, E. (2005). Dear shareholder, dear stockholder, dear stakeholder: The business letter genre in the annual general report. In P. G. M. Gotti (Ed.), Genre variation in business letters (pp. 325-346). Bern: peter Lang.

Plung, D. L., \& Montgomery, T. T. (2004). Professional communication: the corporate insider's approach: Thomson/South-Western.

Prasad, A., \& Mir, R. (2002). Digging deep for meaning: a critical hermeneutic analysis of CEO letters to shareholders in the oil industry. Journal of Business Communication, 39(1), 92-116.

Preston, A. M., Wright, C., \& Young, J. J. (1996). Imag [in] ing annual reports. Accounting, Organizations and Society, 21(1), 113-137.

Rogers, P. S. (2000). CEO Presentations in Conjunction with Earnings Announcements Extending the Construct of Organizational Genre Through Competing Values Profiling and User-Needs Analysis. Management Communication Quarterly, 13(3), 426-485.

Rutherford, B. A. (2005). Genre Analysis of Corporate Annual Report Narratives A Corpus Linguistics-Based Approach. Journal of Business Communication, 42(4), 349-378.

Ryan, G. W., \& Bernard, H. R. (2003). Techniques to identify themes. Field methods, 15(1), 85-109.

Seidman, S. A. (1992). A Study of the Visual Design of Corporate Annual Reports. Journal of Visual Literacy, 12(2).

Thomas, J. (1997). Discourse in the marketplace: the making of meaning in annual reports. Journal of Business Communication, 34(1), 47-66.

Williams, L. S. (2008). The Mission Statement A Corporate Reporting Tool With a Past, Present, and Future. Journal of Business Communication, 45(2), 94-119. 